Supporting Information containing 11 pages, 7 figures and 1 table to accompany manuscript titled

\title{
Oxidative dissolution of silver nanoparticles by chlorine: Implications to silver nanoparticles fate and toxicity
}

\author{
Shikha Garg, Hongyan Rong, Christopher J. Miller and T. David Waite* \\ ${ }^{1}$ School of Civil and Environmental Engineering, The University of New South Wales, \\ Sydney, NSW 2052, Australia
}

Environmental Science and Technology

Revised

March 2016

\footnotetext{
*Corresponding author: Tel. +61-2-9385 5060; FAX +61-2-9385 6139; Email

d.waite@unsw.edu.au
} 


\section{SI-1: Additional experimental details}

\section{SI-1.1: Experimental setup}

All experiments were performed in air-saturated buffer solution at a temperature of $22{ }^{\circ} \mathrm{C}$ unless stated otherwise. To study the reaction of $\mathrm{AgNPs}$ and $\mathrm{OCl}^{-}$, appropriate concentrations of $\mathrm{AgNPs}$ and $\mathrm{OCl}^{-}$stock solutions were added to $30 \mathrm{~mL}$ of air-saturated buffer placed in plastic bottles covered with aluminium foil to avoid interference from outside light. Samples were withdrawn from the reactor manually at a set time for $\mathrm{AgNPs}$ and $\mathrm{OCl}^{-}$measurement. For measurement of dissolved $\mathrm{Ag}(\mathrm{I})$ concentration, samples were withdrawn 30 minutes after the addition of AgNPs and $\mathrm{OCl}^{-}$. To determine the role of dioxygen in the experimental system investigated here, we conducted one set of experiments in which the concentration of dioxygen was reduced by sparging the buffered solution with argon in a sealed reactor for four hours prior to experiments. This sparged buffered solution and the stock solutions of AgNPs and $\mathrm{OCl}^{-}$were placed inside an anaerobic chamber (Plas-Lab Inc $; 5 \% \mathrm{H}_{2}$ in $\mathrm{N}_{2} ;\left[\mathrm{O}_{2}\right]$ $\leq 10 \mathrm{ppm}$ ) and equilibrated in the chamber for 1 hour. The experiments were initiated by adding appropriate volumes of AgNPs and $\mathrm{OCl}^{-}$to the buffered solution. Two samples were withdrawn from the reactor after 30 minutes and mixed with an appropriate concentration of reagent $\left(\mathrm{DPD}+\right.$ phosphate buffer or glycine + phosphate buffer + DPD) for analysis of $\mathrm{OCl}^{-}$. One more sample was taken from the reactor for dissolved $\mathrm{Ag}(\mathrm{I})$ analysis.

\section{SI-1.2: OCI measurement}

As indicated in the main manuscript, the concentration of $\mathrm{OCl}^{-}$was measured using the DPD method. To account for DPD oxidation occurring due to the presence of other oxidants in our experimental matrix, parallel experiments were performed in which $50 \mu \mathrm{M}$ glycine was added prior to DPD addition in order to selectively remove $\mathrm{OCl}^{-}$since glycine converts $\mathrm{OCl}^{-}$

instantaneously into chloroaminoacetic acid. ${ }^{1,2}$ The results shown in Figure S1 do confirm 
that complete consumption of $\mathrm{OCl}^{-}$occurs on the addition of glycine since there is no absorption corresponding to $\mathrm{DPD}^{\circ+}$ when DPD is added to solution containing $\mathrm{OCl}^{-}$and glycine. More tests were performed to ensure that glycine addition does not interfere with measurement of additional DPD oxidants like $\mathrm{H}_{2} \mathrm{O}_{2}$ (data not shown).

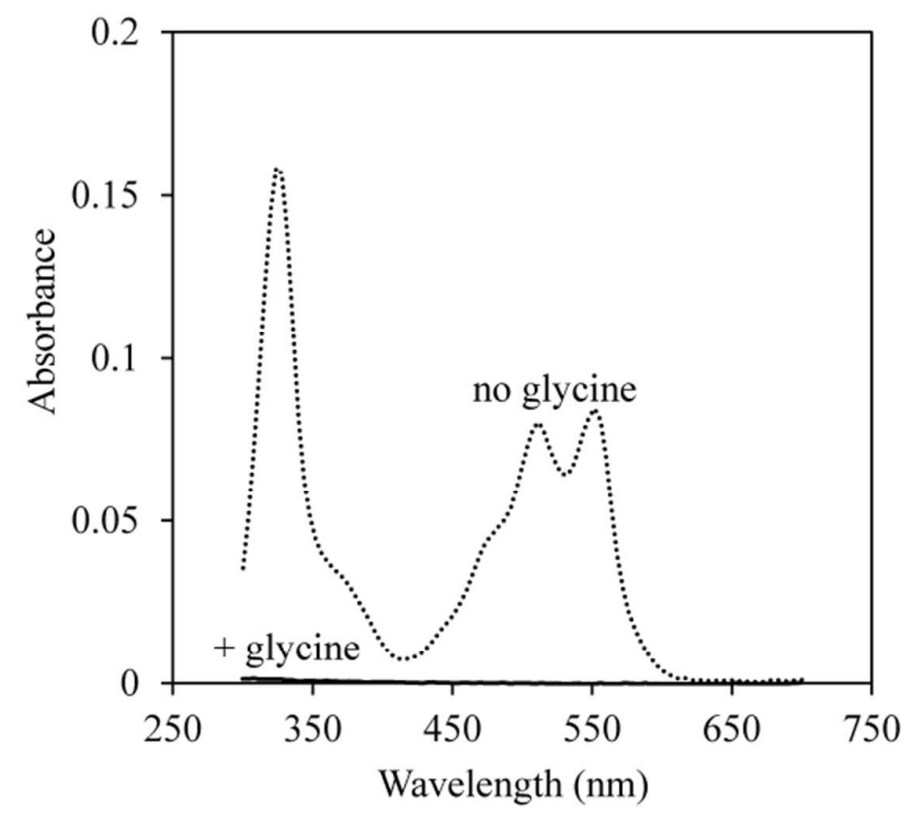

Figure S1: Absorbance measured in $2 \mathrm{mM} \mathrm{NaHCO}_{3}$ buffer solution containing $5 \mu \mathrm{M} \mathrm{OCl}^{-}$on addition of DPD. Dotted line shows the absorbance measured in the absence of glycine while solid line (which is almost zero) shows the absorbance measured in the presence of $50 \mu \mathrm{M}$ glycine.

\section{SI-1.2: Hydrogen peroxide measurement}

Concentrations of $\mathrm{H}_{2} \mathrm{O}_{2}$, generated on reaction of $\mathrm{AgNPs}$ and $\mathrm{OCl}^{-}$, were measured using the DPD method. ${ }^{3}$ Peroxidase from horseradish (HRP) readily combines with $\mathrm{H}_{2} \mathrm{O}_{2}$ with the resultant $\mathrm{HRP}-\mathrm{H}_{2} \mathrm{O}_{2}$ complex oxidizing DPD to DPD ${ }^{\cdot+}$ which exhibits an absorption peak at $551 \mathrm{~nm}^{3}$ For measurement of $\mathrm{H}_{2} \mathrm{O}_{2}, 300 \mu \mathrm{L}$ of $50 \mathrm{mM}$ phosphate buffer $\left(\left[\mathrm{NaH}_{2} \mathrm{PO}_{4}\right]:\left[\mathrm{Na}_{2} \mathrm{HPO}_{4}\right]=3: 1\right)$ and $100 \mu \mathrm{L}$ of $6 \mathrm{mM}$ DPD stock solution were added to 2.6 
$\mathrm{mL}$ of sample in a quartz cuvette and then absorbance was measured. Immediately after measurement $20 \mu \mathrm{L}$ of 50 KU.L ${ }^{-1}$ HRP (Sigma) stock solution was added and then absorbance was recorded again. The difference in the absorbance measured in the presence and the absence of HRP enables determination of the $\mathrm{H}_{2} \mathrm{O}_{2}$ concentration. Calibration was performed by addition of appropriate volumes of $\mathrm{H}_{2} \mathrm{O}_{2}$ stock solution to the experimental matrix. A molar extinction coefficient $18,000 \pm 1000 \mathrm{M}^{-1} \mathrm{~cm}^{-1}$ was achieved which is close to the published value of $21,000 \mathrm{M}^{-1} \mathrm{~cm}^{-1}$. ${ }^{3}$ The stock solution of $\mathrm{H}_{2} \mathrm{O}_{2}$ was standardized by UV spectrometry. $^{4}$

\section{SI-1.3: Hydroxyl radical measurement}

The extent of hydroxyl radical generation from $\mathrm{AgNPs}$ and $\mathrm{OCl}^{-}$reaction was determined using phthalhydrazide as a probe. ${ }^{5}$ For measurement, $\mathrm{AgNPs}$ and $\mathrm{OCl}^{-}$were added to a solution containing $0.55 \mathrm{mM}$ phthalhydrazide and $2 \mathrm{mM} \mathrm{NaHCO} 3$ at $\mathrm{pH}$. Samples were withdrawn from the reactor continuously and mixed with $1 \mathrm{M} \mathrm{Na}_{2} \mathrm{CO}_{3}$ solution (at $\mathrm{pH} 11$ ) and the chemiluminescence was measured over time. Calibration was performed by addition of a 5-HO-Phth standard.

\section{SI-1.4: AgNP measurement}

The change in the concentration of AgNPs was measured using the peak surface plasmon resonance (SPR) absorbance that was observed to occur at $392 \mathrm{~nm}$ under all experimental conditions investigated here (see Figure S2). Since there was no significant $(p>0.1$ using single tailed student $t$-test) shift in the SPR peak during the duration of our experiments (indicating that AgNP aggregation did not occur), the peak SPR absorbance is linearly correlated to the AgNP concentration. 


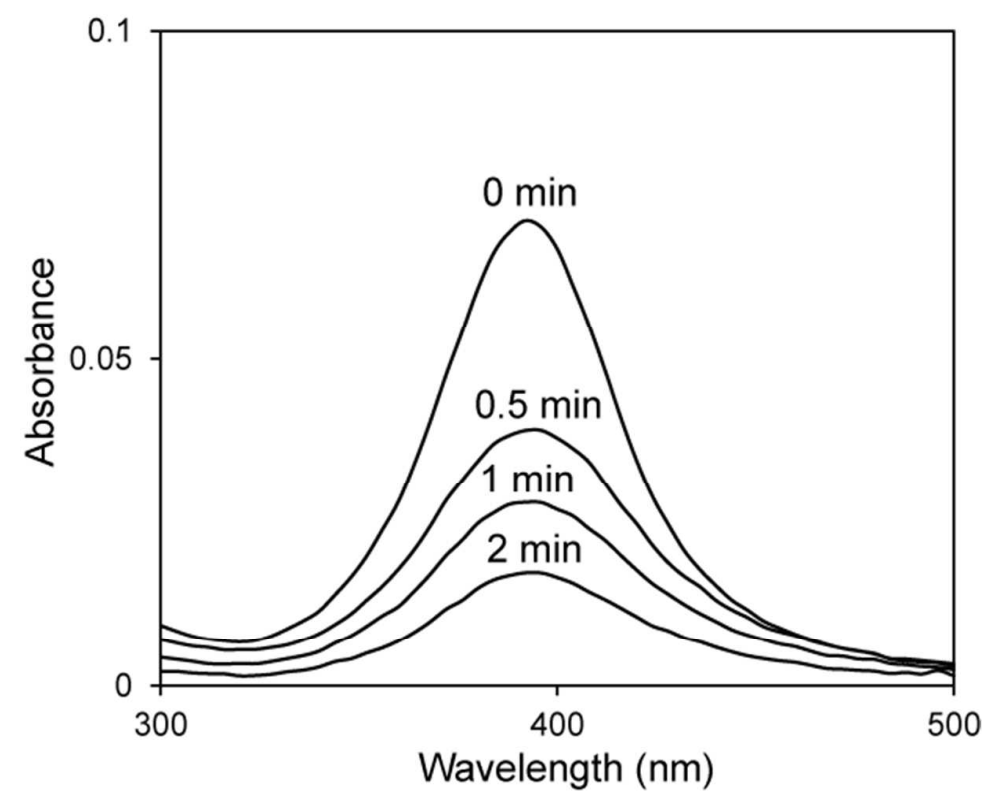

Figure S2: (a) Measured AgNP absorbance in air-saturated $\mathrm{pH} 8$ solution containing $2.5 \mu \mathrm{M}$ $\mathrm{OCl}^{-}$and $5 \mu \mathrm{M}$ AgNPs.

\section{SI-2: Additional experimental results}

\section{SI-2.1 : Total Ag concentration measurement}

The sum of the final AgNPs concentration remaining and the dissolved $\mathrm{Ag}(\mathrm{I})$ concentration formed is slightly less than the initial concentration of AgNPs added in all cases with the difference $(<10 \%)$ possibly due to loss of some dissolved silver during the filtration process while preparing samples for dissolved $\operatorname{Ag}(\mathrm{I})$ measurement. Alternatively, it is possible that there is a loss of $\mathrm{Ag}$ either through $\mathrm{AgNPs}$ aggregation and/or precipitation of $\mathrm{AgCl}(\mathrm{s})$ and/or $\mathrm{Ag}_{2} \mathrm{O}(\mathrm{s})$. However, high resolution TEM analysis of the suspensions containing AgNPs and $\mathrm{OCl}^{-}$revealed no evidence of formation of either $\mathrm{Ag}_{2} \mathrm{O}(\mathrm{s})$ or $\mathrm{AgCl}(\mathrm{s})$ (data not shown) suggesting that loss of silver is most likely due to either loss during filtration or due to aggregation of small amounts of AgNPs. Aggregation of AgNPs will result in small changes in the surface plasmon resonance peak and hence will affect AgNPs quantification. In any 
case, since the loss of silver is $<10 \%$ in all cases, hence we have neglected the effect of this loss pathway in our analysis.

\section{SI-2.2: Initial $\mathrm{OCl}^{-}$decay rate in air-saturated solution}
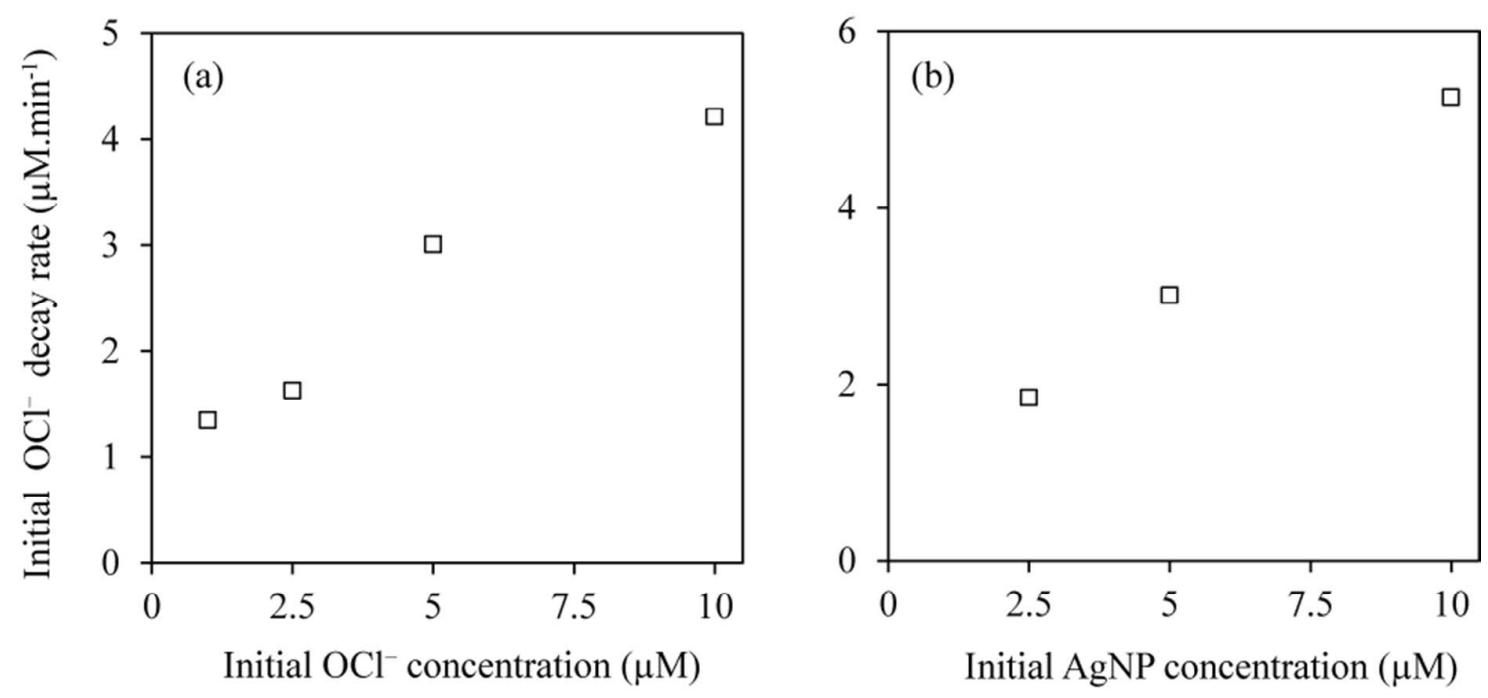

Figure S2: (a) Measured initial $\mathrm{OCl}^{-}$decay rate in air-saturated $\mathrm{pH} 8$ solution containing $\mathrm{OCl}^{-}$and $5 \mu \mathrm{M}$ AgNPs. (b) Measured initial $\mathrm{OCl}^{-}$decay rate in the air-saturated $\mathrm{pH} 8$ solution containing $5 \mu \mathrm{M} \mathrm{OCl}^{-}$and varying AgNPs concentration. The initial $\mathrm{OCl}^{-}$decay rate was calculated using the data point measured at $30 \mathrm{~s}$ shown in Figure 1 for all the experimental conditions investigated. 

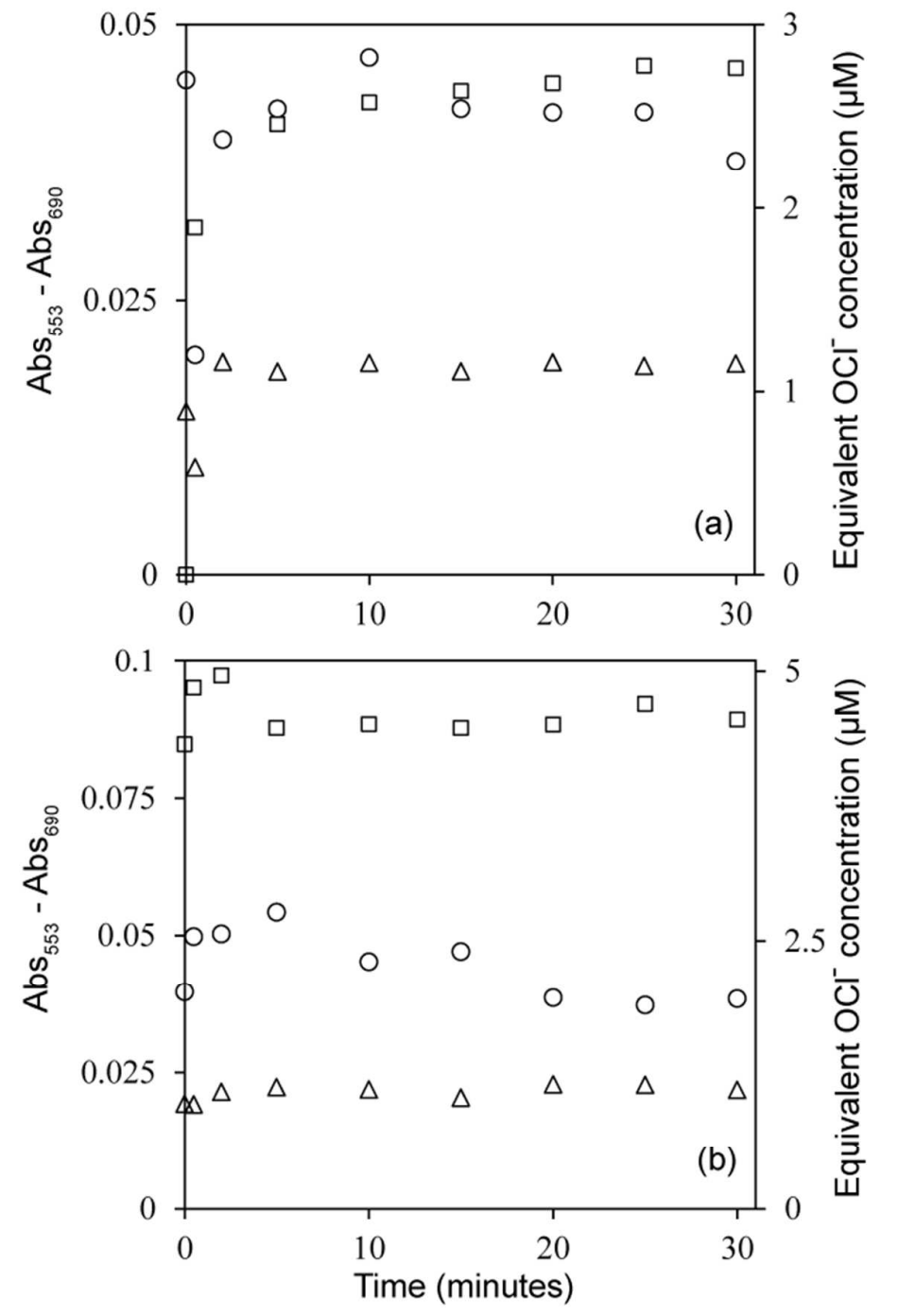

Figure S3: Measured absorbance at $553 \mathrm{~nm}$ corresponding to $\mathrm{DPD}^{\circ+}$ and equivalent concentration of $\mathrm{OCl}^{-}$observed in the air-saturated $\mathrm{pH} 8$ solution containing $5 \mu \mathrm{M}$ AgNPs and $1 \mu \mathrm{M}$ (triangles), $2.5 \mu \mathrm{M}$ (circles) and $5 \mu \mathrm{M}$ (squares) $\mathrm{OCl}^{-}$(a) when glycine is added prior to DPD addition (b) with no glycine addition. The absorbance measured at $553 \mathrm{~nm}$ was corrected for any background absorbance by subtracting the absorbance measured at $690 \mathrm{~nm}$. Points represent the average of duplicate measurements. 


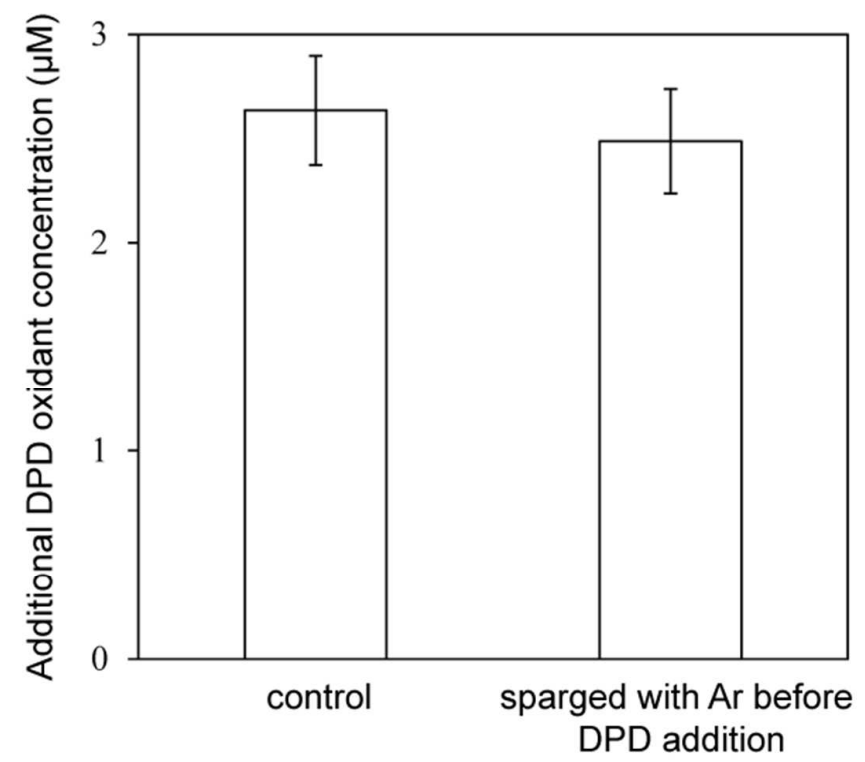

Figure S4: Effect of sparging with argon prior to DPD addition (to remove any volatile compounds such as $\left.\mathrm{ClO}_{2}{ }^{\circ}\right)$ on the concentration of additional DPD oxidant $\left(\mathrm{Cl}_{\text {DPD-ox }}\right)$ formed on reaction of $5 \mu \mathrm{M} \mathrm{OCl}^{-}$and $5 \mu \mathrm{M}$ AgNPs in air saturated solution at $\mathrm{pH} 8$. Data are the average of duplicate measurements and error bars the standard deviation of duplicate measurements.

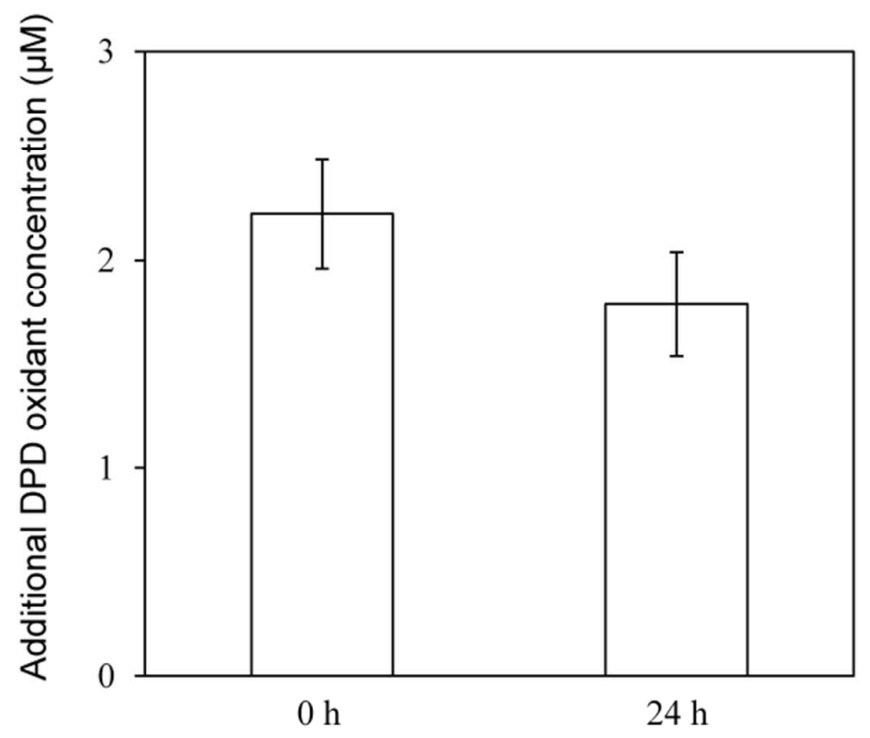

Time delay between addition of DPD and completion of AgNP oxidation by chlorine

Figure S5: Effect of time delay between DPD addition and completion of oxidative dissolution of $5 \mu \mathrm{M}$ AgNPs by $5 \mu \mathrm{M} \mathrm{OCl}^{-}$on the concentration of the $\mathrm{Cl}_{\mathrm{DPD}-\mathrm{ox}}$ formed during 
the reaction, which was complete 30 minutes after addition of AgNPs and $\mathrm{OCl}^{-}$to the airsaturated $\mathrm{pH} 8$ solutions. Data are the average of duplicate measurements and error bars the standard deviation of duplicate measurements.
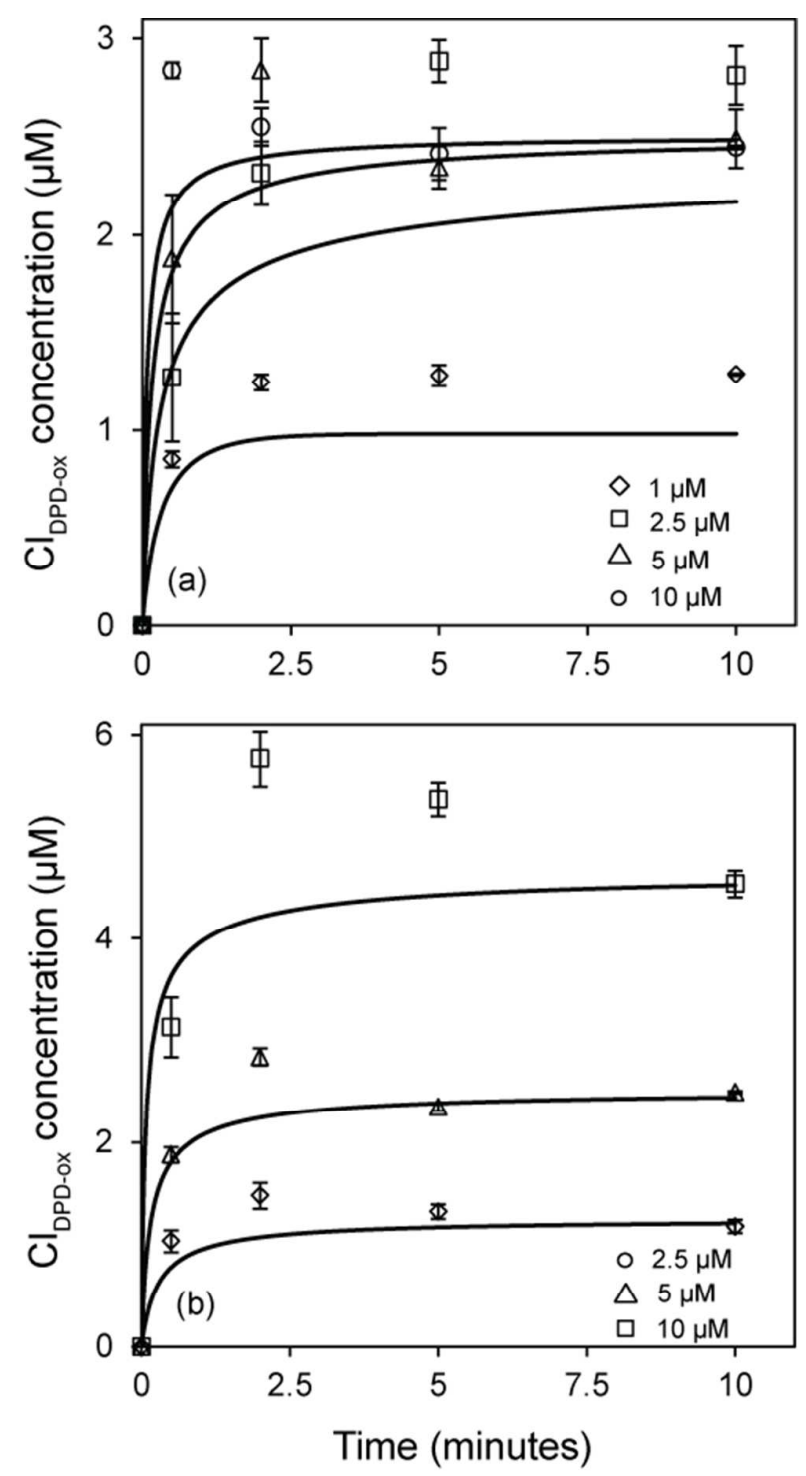

Figure S6: (a) Concentration of $\mathrm{Cl}_{\mathrm{DPD}-\mathrm{ox}}$ formed on reaction of $5 \mu \mathrm{M}$ AgNPs with varying $\mathrm{OCl}^{-}$concentration (indicated on the plot) in air-saturated solutions at $\mathrm{pH}$ 8. (b) Concentration of $\mathrm{Cl}_{\mathrm{DPD}-\mathrm{ox}}$ formed on reaction of $5 \mu \mathrm{M} \mathrm{OCl}{ }^{-}$in the presence of varying AgNPs concentration (indicated on the plot) in air-saturated solutions at $\mathrm{pH}$ 8. Points 
represent the average of triplicate measurements; lines represent model values. Error bars represents the standard deviation of triplicate measurements.

It is to be noted that the concentration of the $\mathrm{Cl}_{\mathrm{DPD}-\mathrm{ox}}$ formed here is determined by measuring the absorbance corresponding to $\mathrm{DPD}^{*+}$ in the presence of glycine and hence cannot be due to any unreacted $\mathrm{OCl}^{-}$since any $\mathrm{OCl}^{-}$present will be consumed on glycine addition.

\section{SI-3: Details of the kinetic model developed to explain AgNPs- $\mathrm{OCl}^{-}$interaction}

A kinetic model assuming that that the stoichiometry of $\mathrm{Ag}(\mathrm{I})$ formation to $\mathrm{OCl}^{-}$decay is controlled by formation of a reactive intermediate in a $2: 1$ stoichiometric reaction between AgNPs and $\mathrm{OCl}^{-}$is shown in Table $\mathrm{S} 1$. We describe the various reactions used and justification of the rate constant used in detail below.

Formation of the reactive intermediate: Reaction 1 represents the formation of the reactive intermediate in the stoichiometric ratio of 2:1 for AgNPs: $\mathrm{OCl}^{-}$reaction. The rate constant for this reaction was determined based on the best-fit to our experimental results observed in airsaturated solution (Figures 1-2 and S6).

Formation of $\mathbf{A g}(\mathbf{I})$ in air-saturated solution: Reaction 2 represents the oxidation of the reactive intermediate by dioxygen resulting in formation of $\mathrm{Ag}^{+}$and additional DPD oxidant. The rate constant for this reaction was determined based on the best-fit to our experimental results in air-saturated solution (Figures 1-2 and S6). Note that this may not represent the actual reaction but an overall reaction incorporating all the intermediate steps resulting in formation of $\mathrm{Ag}^{+}$and $\mathrm{Cl}_{\mathrm{DPD}-\mathrm{ox}}$.

Formation of $\mathbf{A g}(\mathbf{I})$ in deoxygenated solution: Reaction 3 represents the oxidation of AgNPs by $\mathrm{OCl}^{-}$resulting in formation of $\mathrm{Ag}^{+}, \mathrm{Cl}_{\text {DPD-ox }}$ and another chlorine specie which is 
not capable of oxidizing DPD $\left(\mathrm{Cl}_{\text {no-DPD-ox }}\right)$. This reaction is important under deoxygenated condition in the presence of excess $\mathrm{OCl}^{-}$. The rate constant for this reaction was determined based on the best-fit to $\mathrm{Ag}^{+}$generation in the deoxygenated solution (Figure 3).

Catalytic decay of $\mathrm{OCl}^{-}$by AgNPs in deoxygenated solution: Reaction 4 and 5 represents the catalytic decay of $\mathrm{OCl}^{-}$by AgNPs in the deoxygenated solution in presence of excess AgNPs. The reaction of the reactive intermediate with AgNPs initially results in the formation of an oxidized $\mathrm{Ag}$ species i.e. $\mathrm{Ag}^{+}$and a reduced $\mathrm{Ag}$ species i.e. charged $\mathrm{AgNPs}^{6}$ which react together to reform AgNPs with resultant removal of $\mathrm{OCl}^{-}$to form $\mathrm{Cl}_{\text {no-DPD-ox }}$ and $\mathrm{Cl}_{\text {DPD-ox }}$. The reaction of the charged AgNPs with dioxygen, which is reported to occur in earlier studies, ${ }^{6}$ is not included here since the formation of these charged AgNPs occur only in the absence of dioxygen under the experimental conditions investigated here.

Table S1: A kinetic model to explain oxidation of AgNPs by $\mathrm{OCl}^{-}$

\begin{tabular}{llc}
\hline $\begin{array}{c}\text { Reaction } \\
\text { no }\end{array}$ & \multicolumn{1}{c}{ Reaction } & $\begin{array}{c}\text { Rate constant } \\
\text { used }\end{array}$ \\
\hline 1 & $2 \mathrm{Ag}^{0}+\mathrm{OCl}^{-} \longrightarrow 2 \mathrm{Ag}^{0} \ldots \mathrm{OCl}^{-}$ & $2.5 \times 10^{9} \mathrm{M}^{-3} \mathrm{~s}^{-1}$ \\
2 & $2 \mathrm{Ag}^{0} \ldots \mathrm{OCl}^{-}+\mathrm{O}_{2} \longrightarrow 2 \mathrm{Ag}^{+}+\mathrm{Cl}_{\mathrm{DPD}-\mathrm{ox}}$ & $\geq 1 \times 10^{6} \mathrm{M}^{-1} \mathrm{~s}^{-1}$ \\
3 & $2 \mathrm{Ag}^{0} \ldots \mathrm{OCl}^{-}+\mathrm{OCl}^{-} \longrightarrow 2 \mathrm{Ag}^{+}+\mathrm{Cl}_{\mathrm{DPD}-\mathrm{ox}}+\mathrm{Cl}_{\mathrm{no}-\mathrm{DPD}-\mathrm{ox}}$ & $1 \times 10^{7} \mathrm{M}^{-1} \mathrm{~s}^{-1}$ \\
4 & $2 \mathrm{Ag}^{0} \ldots \mathrm{OCl}^{-}+\mathrm{Ag}^{0} \longrightarrow 2 \mathrm{Ag}^{0 *}+\mathrm{Ag}^{+}+\frac{1}{2} \mathrm{Cl}_{\mathrm{no}-\mathrm{DPD}-\mathrm{ox}}+\frac{1}{2} \mathrm{Cl}_{\mathrm{DPD}-\mathrm{ox}}$ & $1 \times 10^{6} \mathrm{M}^{-1} \mathrm{~s}^{-1}$ \\
& & \\
& $\mathrm{Ag}^{0^{*}}+\mathrm{Ag}^{+} \longrightarrow \mathrm{Ag}^{0}+\mathrm{Ag}^{0}$ & $\geq 1 \times 10^{6} \mathrm{M}^{-1} \mathrm{~s}^{-1}$ \\
\hline
\end{tabular}




\section{References}

1. Peskin, A. V.; Midwinter, R. G.; Harwood, D. T.; Winterbourn, C. C., Chlorine transfer between glycine, taurine, and histamine: Reaction rates and impact on cellular reactivity. Free Radical Biol. Med. 2004, 37, 1622-1630.

2. Standard Methods For the Examination of Water and Wastewater. American Public Health Association, American Water Works Association, Water Environment Federation: The United States of America, 1998.

3. Bader, H.; Sturzenegger, V.; Hoigne, J., Photometric-Method for the Determination of Low Concentrations of Hydrogen-Peroxide by the Peroxidase Catalyzed Oxidation of N,NDiethyl-P-Phenylenediamine (Dpd). Water Res 1988, 22, (9), 1109-1115.

4. Morgan, M. S.; Van Trieste, P. F.; Garlick, S. M.; Mahon, M. J.; Smith, A. L., Ultraviolet molar absorptivities of aqueous hydrogen peroxide and hydroperoxyl ion. Anal Chim Acta 1988, 215, 325-329.

5. Miller, C. J.; Rose, A. L.; Waite, T. D., Phthalhydrazide chemiluminescence method for determination of hydroxyl radical production: Modifications and adaptations for use in natural systems. Anal Chem 2011, 83, (1), 261-268.

6. He, D.; Garg, S.; Waite, T. D., H2O2-mediated Oxidation of Zero-valent Silver and Resultant Interactions between Silver Nanoparticles, Silver Ions and Reactive Oxygen Species. Langmuir 2012, 28, 10266-10275. 